\title{
FORMAÇÃO, TRANSFORMAÇÃO, ADAPTAÇÃO: ORIGENS DE UMA INSTITUIÇÃO EDUCATIVA CONFESSIONAL BATISTA EM BELO HORIZONTE/MG, DÉCADA DE 1920 \\ DOI: http://dx.doi.org/10.1590/2236-3459/35073
}

\author{
Taciana Brasil dos Santos \\ Universidade Federal de Minas Gerais, Brasil.
}

\section{$\cos 80$}

\begin{abstract}
Resumo
A partir da segunda metade do século 19 chegaram ao Brasil os primeiros missionários protestantes norte-norte-americanos e a educação escolar foi uma das principais formas de difusão de sua mensagem. Este trabalho tem por objetivo discorrer acerca das condições de criação e funcionamento inicial de uma instituição educativa criada pelos batistas na capital de Minas Gerais. Será tratado acerca das expectativas de norte-norte-americanos e brasileiros para seu funcionamento, das representações criadas em torno da instituição e de sua forma de inserção no contexto educacional e escolar da capital mineira à época.

Palavras-chave: educação escolar, educação confessional, protestantismo.
\end{abstract}

\section{FORMATION, TRANSFORMATION, ADAPTATION: THE ORIGINS OF AN EDUCATIONAL INSTITUTION CONFESSIONAL BAPTIST IN BELO HORIZONTE/MG, $1920^{\text {s }}$}

\begin{abstract}
From the second half of the nineteenth century, came to Brazil the first few American Protestant missionaries. School education was one of the main ways to disseminate their message in our territory. This paper aims to talk about the conditions of establishment and initial operation of an educational institution created by the Baptists in the capital of Minas Gerais. Will be treated on the expectations of Americans and Brazilians to their operation, the representations created around the institution, and its insertion in the educational context of the town at the time.

Key-words: school education; confessional education; protestantism.
\end{abstract}




\section{FORMACIÓN, TRANSFORMACIÓN, ADAPTACIÓN: LOS ORÍGENES \\ DE UNA INSTITUCIÓN EDUCATIVO CONFESIONAL BAUTISTA \\ EN BELO HORIZONTE/MG, DÉCADA DE 1920}

\section{Resumen}

A partir de la segunda mitad del siglo 19, llegó a Brasil los primeros misioneros protestantes nortenorte-americanos. La educación escolar es uno de los principales medios de difusión de su mensaje en nuestro territorio. Este trabajo tiene como objetivo discutir sobre las condiciones de establecimiento y funcionamiento inicial de una institución educativa creada por los Bautistas en la capital de Minas Gerais. Serán tratados en las expectativas de los estadounidenses y brasileños a su funcionamiento, las representaciones creadas en torno a la institución y su inserción en el contexto educativo de la ciudad en ese momento.

Palabras-clave: educación escolar, educación confesional, protestantismo.

\section{FORMATION, LA TRANSFORMATION, L'ADAPTATION: LES ORIGINES D'UN ÉTABLISSEMENT D'ENSEIGNEMENT CONFESSIONNEL BAPTISTE À BELO HORIZONTE/MG, DÉCENNIE 1920}

\section{Résumé}

A partir de la seconde moitié du 19e siècle, est venu au Brésil les premiers missionnaires protestants américains. L'éducation scolaire a été l'un des principaux moyens de diffusion de leur message sur notre territoire. Cet article vise à discuter sur les conditions d'établissement et d'exploitation initiale d'un établissement d'enseignement créé par les baptistes dans la capitale du Minas Gerais. Seront traités sur les attentes des Américains et les Brésiliens à leur fonctionnement, les représentations créées autour de l'institution et de son insertion dans le contexte éducatif de la ville à l'époque.

Mots-clé: éducation scolaire, l'enseignement confessionnel, protestantisme. 
o final do século 19 chegava ao Brasil o protestantismo de missão. Por meio de missionários, homens e mulheres, de diversas denominações ${ }^{1}$

protestantes norte-americanas, realizaram trabalho proselitista no país. Este trabalho, porém, ia além da disseminação de princípios religiosos, ao propor estender-se à americanização dos modos de vida do brasileiro, tanto na esfera pública, quanto privada (Mendonça; Velasques Filho, 2002).

Além da área eclesiástica e do proselitismo, uma das áreas preferidas para atuação pelos missionários foi a educação escolar. Em todo o Brasil podemos encontrar colégios confessionais protestantes centenários, das mais diversas denominações, construídos, normalmente, com recursos norte-norte-americanos, com o objetivo de civilizar o brasileiro. Muitas pesquisas têm sido feitas com relação a estas instituições como, por exemplo, os metodistas de Peri Mesquida (1994), os presbiterianos de Nascimento (2007) e Clark (2009) e os batistas de Cleni da Silva (2004) e Machado (1999).

Neste trabalho trataremos acerca de uma instituição batista. A igreja batista foi um dos grupos que mais tardiamente se inseriu no Brasil, apenas em 1881 foi enviado o primeiro missionário para trabalhar com brasileiros (Pereira, 1979). Os batistas eram um grupo minoritário nos Estados Unidos (Azevedo, 1996) e essa posição refletia-se na obra missionária realizada no Brasil, muito mais tímida que a dos metodistas, por exemplo.

Em geral, os missionários preferiam as cidades maiores, como Rio de Janeiro, São Paulo, Salvador e Recife (Harrison, 1987). Quando seu interesse por Minas Gerais se despertou, a então capital Ouro Preto também não recebeu investimentos missionários: os norte-americanos preferiram tentar adentrar o Estado por Juiz de Fora e outras cidades da Zona da Mata Mineira, sem ter sucesso neste primeiro momento ( $O$ Jornal Batista, 1982).

É possível que o interesse por Belo Horizonte tenha surgido por diversas razões. As representações acerca da nova capital como uma cidade republicana (Mello, 1996) iam ao encontro das expectativas dos batistas para a transformação da sociedade brasileira (Barbosa, 1920). A circulação financeira e de imigrantes relacionada ao cultivo cafeeiro também pode ter atraído os missionários, já que eles necessitavam de pessoas para converter e dinheiro para manter o trabalho. A facilidade de locomoção pelas estradas de ferro também pode ter contado a favor do estabelecimento destes norte-norte-americanos em Belo Horizonte.

Embora tardio e sem a definição de uma motivação única para o interesse por Belo Horizonte, o investimento batista proporcionou a criação de um colégio que se tornou no futuro referência e modelo para todos os colégios batistas no Brasil ( $O$ Jornal Batista, 1982). Este trabalho tem por objetivo discorrer acerca das condições de criação e

\footnotetext{
${ }^{1}$ Compreende-se o termo denominação como o nome genérico atribuído aos diferentes grupos de cristãos protestantes. De acordo com Gonzalez (1991, p. 22), "este termo se relaciona com uma forma de pensar muito popular no cristianismo norte-americano: a Igreja verdadeira é invisível, e consiste de todos os crentes; as igrejas são organizações voluntárias de membros da lgreja, que se reúnem segundo as suas convicções e desejos".
} 
funcionamento inicial deste colégio, das expectativas de norte-americanos e brasileiros acerca de seu funcionamento, das representações ${ }^{2}$ criadas em torno da instituição e de sua forma de inserção no contexto educacional e escolar da capital mineira à época.

Fundada em 1918 como Escola Baptista de Bello Horizonte - EBBH -, a principal instituição escolar batista mineira passou por diversas transformações ao longo de seus primeiros anos. Sua origem, conforme nos relata o pastor Henrique Cockell em 50 anos (1968), parecia integrar interesses, tanto da denominação, quanto das famílias dos pastores. Desejava-se uma escola que conformasse as crianças dentro dos princípios batistas, princípios que muitas vezes ultrapassavam os limites religiosos. Para alcançar este objetivo o modelo disciplinar do colégio, particularmente do internato, revelava-se bastante útil, já que possibilitava um controle quase total dos anos da infância e adolescência dos alunos. Esse controle permitia, inclusive, que os pastores e missionários conhecessem suficientemente as crianças disponíveis entre as famílias da denominação, para dentre elas escolher aqueles quer Ihes sucederiam no futuro, tanto no trabalho evangelístico e eclesiástico, quanto no educacional.

O nome Escola, adotado na fundação, é a designação comum utilizada entre os batistas para instituições escolares que tinham por objetivo ensinar apenas as primeiras letras ou que, no máximo, ofereciam o curso primário (Crabtree, 1940). Considerando a experiência argentina, é possível observar que, normalmente, a Escola era anexa ao templo e funcionava quase que como uma extensão da igreja. Não havia intenção de grande expansão numérica de alunos ou de níveis de ensino, bem como parecia ser na maioria das vezes constituída de uma classe única. Os planos de ação da instituição dispunham de certa liberdade, desde que estivessem em concordância com os princípios da instituição.

Geralmente todos os assuntos relacionados à escola eram decididos pela diretora, salvo raríssimas exceções, mulheres, muitas vezes solteiras e acumulando a função da docência (Rodriguez, 1936). Esta definição concorda com a descrição realizada por Dallabrida (2004) acerca da educação da infância das classes populares na modernidade, em que thes era oferecido o aprendizado das primeiras letras, da doutrina cristã e de um ofício, embora não haja indícios de que as escolas batistas se dedicassem a este último objetivo. Concorda também com a descrição das escolas isoladas feita por Faria Filho (2000), normalmente funcionando em um prédio que não foi construído para fins educacionais e sempre com recursos materiais limitados.

As condições de criação da EBBH apontam para uma situação bem semelhante à argentina: funcionando nas instalações da igreja, um salão comercial alugado, muito provavelmente não haveria espaço para mais do que uma classe única (50 anos, 1968). A configuração inicial da EBBH parece ter sido bastante semelhante à das escolas isoladas, tão comuns em Belo Horizonte à época de sua fundação. Isso pode ter sido um problema para a instituição. De acordo com Faria Filho (2000), na imprensa da capital mineira do

\footnotetext{
${ }^{2}$ Roger Chartier (1990) define representação como a forma que as realidades sociais são percebidas e interpretadas, considerando que esta leitura nunca é dotada de neutralidade. Cada grupo percebe a realidade de uma maneira, e para que uma interpretação prevaleça, outra deve ser menosprezada. A construção de uma visão da realidade permite que sejam criadas identidades sociais, que tornam visível a existência de um grupo, classe ou comunidade. 
início do século 20, era comum encontrar representações acerca das escolas isoladas como inadequadas e causadoras do atraso escolar.

Os grupos escolares eram, comumente, representados como modernos, eficientes, higiênicos, republicanos e adequados ao projeto civilizatório que se levava a efeito pela construção de uma nova capital para Minas Gerais. Diante dessas representações negativas a respeito das escolas isoladas, estas, muito provavelmente, foram consideradas pelos missionários inadequadas à instituição batista, principalmente se considerarmos seu empenho em se representar como republicanos e democráticos, tanto no ambiente eclesiástico, quanto educacional. Talvez este tenha sido um dos motivos que levaram à precoce transformação em Collegio. Pode ter apressado ainda mais esta transformação a concorrência com o Colégio Izabela Hendrix, igualmente confessional e protestante, embora metodista.

Conforme evidencia foto do acervo do Arquivo Público Mineiro, desde 1905 trabalhavam nesta escola uma diretora e cinco professoras, número suficiente para garantir o funcionamento ao menos do curso primário em classes seriadas. De acordo com Faria Filho (2000), no discurso educacional do início do século 20 , a organização escolar em classes seriadas, com instalações adequadas e um profissional na direção, típica dos grupos escolares, era representada como adequada à nova capital mineira, além de moderna e republicana. Como os batistas pretendiam criar, acerca de sua instituição escolar, estas mesmas representações, seria necessário realizar significativas alterações na organização de seu trabalho educacional.

Os Collegios batistas contavam com um apoio muito maior da Convenção do Sul, sendo que diversos missionários foram enviados para o Brasil, especialmente com a finalidade de atuar na educação escolar ou teológica. A presença masculina era muito mais marcante, tanto na docência, quanto na direção. Buscava-se atingir todos os níveis de ensino. De acordo com o prospecto de 1924 eram oferecidos, na instituição mineira, jardim de infância, dois anos; curso primário, três anos; curso médio, três anos; curso preparatorio gymnasial, três anos; curso superior gymnasial, três anos; curso normal, três anos, e uma escola noturna, para formação de adultos. Esta divisão era mais parecida com a realizada na escolarização norte-americana, com um sistema de dois anos de préescola, 12 anos correspondentes à Elementary, Middle e High School, e mais três anos dedicados ao ensino superior. No caso da instituição mineira, as opções eram o seminário para os homens e o magistério para as mulheres.

É curioso que a subdivisão do ensino descrita no parágrafo anterior seja divulgada pelos prospectos de propaganda não apareça refletida no Archivo de notas finaes. Neste documento constam os níveis Jardim, de um ano de duração; Primário, de 6 anos de duração; e Secundário. Não há uma definição exata a respeito da duração desta modalidade: na maioria dos casos, o aluno interrompia o curso após o terceiro ano, sendo que alguns cursavam quatro anos e um único aluno cursou cinco anos. Esse aluno, no futuro, ocupou postos de docência e ministério pastoral dentro da denominação, o que nos leva a questionar se a duração de seu curso não se deveu ao fato de cursar disciplinas do Magistério e do Seminário. Considerando, porém, a divisão de gênero entre os cursos e as tarefas, é bem pouco provável que esta tenha sido a explicação para esse 
caso. Outro fator a se considerar é que o referido aluno já chegou ao Collégio Baptista de Bello Horizonte - CBAM - em um processo adiantado de escolarização, que nos leva a refletir acerca da forma como esta instituição aproveitava os estudos realizados em outras instituições. Dentre as fontes pesquisadas não há qualquer documento sobre o assunto.

Acerca do jardim de infância, há uma pesquisa que trata sobre o tema em recorte temporal próximo ao estudado. Carla Chamon (2005) escreveu, em sua tese de doutoramento, a trajetória de Maria Guilhermina Loureiro de Andrade, educadora presbiteriana de formação froebeliana cuja atuação no campo educacional terminou no ano de 1913. Divulgadora do kindergarten, concebia este nível de ensino não apenas como um lugar, "mas também uma cultura, uma série de meios e procedimentos, com fins e princípios determinados" (Chamon, 2005, p. 258). Para a educadora, durante o jardim de infância e o ensino primário o professor não deveria transmitir conhecimentos, mas levar os alunos a experiências que permitissem o desenvolvimento harmônico das faculdades da criança e sua individualidade.

Estas características, porém, não parecem corresponder ao trabalho realizado no jardim de infância do CBAM em seus primeiros anos, descrito no prospecto de 1921 da seguinte maneira: "Este curso tem como objetivo encaminhar a creança pelos methodos mais práticos para aprender a brincar em collectividade, a ler, escrever e contar com lições simples e faceis, sómente para adquirir a pratica para os cursos seguintes" (1921, s.p.). Como se pode observar, há uma ênfase na aprendizagem de conteúdos escolares, pelos quais o aluno seria capacitado para prosseguir nos próximos níveis de estudo. Esta metodologia de trabalho muito provavelmente não agradou as famílias que se interessavam em matricular seus filhos na instituição devido aos métodos modernos de ensino, considerando o baixo número de matrículas para a modalidade. Talvez por isso, em 1924, o prospecto tenha acrescentado à descrição dessa modalidade de ensino as seguintes sentenças:

Seguimos a orientação de Froebel. Seguem-se durante seis annos os cursos primários e médios, que podem ser classificados como elementares, os quaes correspondem a epochas psychologicas em que a creança está recebendo a maioria das idéas pelos cinco sentidos. Guiamonos pelo programma de ensino, já bastante elaborado. (Propecto, 1924, s. p.)

O Prospecto passou a representar o jardim de infância, curso primário e curso médio como uma unidade. A maneira como é descrita a aquisição de conhecimento corresponde à teoria froebeliana e faz-se questão de citar o nome deste. Percebe-se, nestas linhas, a tentativa do CBAM de se representar como uma instituição preparada para atender esta demanda, de acordo com os princípios de modernidade educacional vigentes à época. Porém, a afirmação a respeito do programa de ensino, descrito como já bastante elaborado, indica que, provavelmente, o jardim de infância da instituição tinha a fama de não corresponder às expectativas quanto a essa modalidade de ensino em uma perspectiva escolanovista, devido a não ter um programa de ensino bem desenvolvido. Talvez por isso o número de matrículas para a modalidade tenha aumentado tanto em 
1925 e 1926, passando a significar cerca de um terço das matrículas ${ }^{3}$. Em 1927 o Prospecto não descreve o jardim de infância. Essa modalidade aparece junto com o primário, cujos conteúdos são descritos e os materiais e livros didáticos relacionados. Percebe-se, nesta descrição, a ênfase no uso de materiais que possibilitavam o ensino intuitivo, além de livros norte-americanos. Para exercitar a leitura, seriam utilizados livros de Maria Guilhermina Loureiro de Andrade.

Quanto à escola noturna, embora inicialmente só oferecesse aulas de português e matemática aos adultos $^{4}$, os prospectos de 1926 e 1927 demonstram que foram acrescidos cursos de inglês, francês, datilografia, desenho prático e técnico, e um curso comercial-conteúdos voltados à formação econômica ou capitalista, concordando com a análise de Hilsdorf (2007) acerca das escolas protestantes à época. O curso normal também era oferecido na instituição. Existiam práticas específicas para o financiamento do curso às alunas pobres, que serão discutidas mais adiante. Em todos os prospectos há uma representação fotográfica das estudantes deste curso.

O Seminário, ou preparação de rapazes para o ministério, também é comumente oferecido pelos Collegios batistas no Brasil. Em Minas Gerais esse curso só foi oferecido no Prospecto a partir do ano de 1924 e apenas em 1927 a classe parece estar realmente funcionando, pois apenas a partir de então são veiculadas fotografias de seus alunos. Os constantes apelos no periódico O Baptista Mineiro, no ano de 1926, para o ingresso de rapazes na classe teológica ajudam a reforçar esta hipótese.

A configuração do CBAM coincide, em muitos aspectos, com a descrição realizada por Dallabrida (2004) a respeito dos colégios na modernidade. Tratava-se de instituições que realizavam uma divisão cronológica na sociedade: os adultos e a juventude. As crianças das classes mais abastadas deveriam ser confinadas nos colégios, onde aprenderiam os saberes considerados necessários e seriam separadas dos adultos. Pineau (2008) afirma que essa separação seria realizada desde a infância até o desenvolvimento do instinto sexual, quando o jovem chegaria a ser pai e então passaria a educar.

Todas essas características compõem a ação disciplinar para a infância e juventude no âmbito do CBAM. Afastadas dos adultos e de sua influência, seria mais fácil instituir a disciplina dos princípios batistas: ao invés de atuar negativamente e corretivamente, esta disciplina atuaria na capacitação e formação dos futuros adultos, integrantes de uma sociedade que se almejava transformada. Os alunos eram disciplinados e capacitados em conformidade com os princípios da denominação, tendo sua saída da instituição prevista para o dia em que estivessem aptos, física e socialmente, para a total reprodução e disseminação dos princípios disciplinares ali incorporados.

$\mathrm{Na}$ capacitação oferecida aos discentes do CBAM, não seriam desconsiderados os aspectos referentes aos papéis atribuídos a cada gênero na doutrina batista. Embora as crianças de ambos os sexos passassem a infância e a adolescência juntas no CBAM, em um ambiente de educação mista, na ocasião da definição do papel que exerceriam na

\footnotetext{
${ }^{3}$ Apesar de as matrículas para o jardim de infância terem sofrido um significativo aumento proporcional, esse aumento não foi expressivo em termos numéricos, dada a diminuição do total de alunos matriculados no período.

${ }^{4}$ Nas fontes consultadas, não obtive qualquer referência acerca da identidade ou rendimento escolar dos alunos e alunas do Curso Nocturno, Magistério e Seminário. 
sociedade, pela sua formação, era vedado às moças o seminário. A elas seria possível apenas o curso normal, suficiente para lhes conferir um cargo valorizado no âmbito da igreja, mas não o posto de maior prestígio, como pastoras.

Aos rapazes que cursassem o seminário a docência não lhes seria vedada, muito pelo contrário, parecia até mesmo ser estimulada em determinados casos. Dessa maneira, o CBAM possibilitava uma ascensão social das mulheres pela docência, mas lhe limitava o posto máximo da denominação. Já os homens tinham uma posição mais privilegiada enquanto pastores e ainda possuíam livre acesso à docência. Conclui-se daí que um dos aspectos da disciplina batista é a submissão feminina perante o masculino, embora fosse reconhecida no grupo a possibilidade de contribuição social extradoméstica da mulher. Esta contribuição, porém, deveria se limitar à docência.

Retomando as origens da instituição, a fundação da EBBH ocorreu em $1^{\circ}$ de março de 1918, em uma assembleia realizada na Primeira Igreja Batista de Belo Horizonte. A diretora/professora era Efigênia Maddox, esposa do missionário Ottis Maddox. Era costume da sra. Maddox manter uma escola doméstica em todos os lugares onde residiu com seu esposo (50 anos, 1968). Não há um consenso acerca do primeiro local de funcionamento da Escola: enquanto os livros comemorativos da instituição ( $O$ Colégio Batista Mineiro: 40 aniversário, 1958; 50 anos, 1968) defendem que desde o início foram utilizadas as instalações da igreja, o relato biográfico escrito pela nora de Efigênia (Maddox, 2008) afirma que sua casa abrigou a instituição até que, devido ao aumento no número de alunos, não fosse mais possível. Uma possibilidade de consenso entre essas duas hipóteses seria o funcionamento das classes na Primeira Igreja Batista de Belo Horizonte e do internato na casa dos Maddox.

A Ata de Abertura da Escola Baptista em Bello Horizonte (O Colégio Batista Mineiro, 1958) revela, em parte, algumas das expectativas dos batistas acerca da instituição e as diferenças entre a percepção de um missionário americano, um pastor brasileiro e um fiel. Passaremos, a seguir, a analisar alguns elementos presentes nesta Ata que possibilitam a percepção de representações circulantes entre o grupo acerca da instituição que estava sendo criada.

De acordo com a Ata a assembleia reunida na Primeira Igreja Batista em Belo Horizonte fundou a EBBH. Iniciou-se a reunião entoando coletivamente o hino 140 do Cantor Cristão, denominado Domingo:

Domingo, ó dia de amor

Tão cheio de prazer!

Almejo, ó meu Senhor

A graça e Teu poder;

Honrar-te, sim, Glorioso Rei,

Cumprir a Tua Santa Lei.

Encher-me vem, Senhor

De gozo e muita fé;

Ó Grande Benfeitor,

Concede-me a mercê

De pecadores despertar

E Tua Igreja estimular! 
Espírito de Luz

Oh! Dá-me o dom do amor

Que vejo em meu Jesus,

O meigo e Bom Pastor

Ensina-me, pois, meu dever

Dirige todo o meu viver. (Cantor Cristão, 1971)

Cabe salientar que esta assembleia de organização do CBAM aconteceu em uma manhã de sexta-feira. É impossível, a partir dos documentos disponíveis, concluir a razão da escolha do hino 140. A partir da análise de sua letra é possível realizar uma série de interpretações a respeito destas razões e considerar o que levou esta escolha, aparentemente equivocada, a ser realizada na ocasião.

Percebe-se, inicialmente, uma variedade de elementos no hino que permitem que se interprete a atividade educativa como sendo diretamente ligada à interpretação teológica do mundo realizada pelo grupo. Note-se que seu título é Domingo. O domingo, dentro da liturgia protestante, é o principal dia de culto. A utilização deste hino denota que os batistas interpretavam a criação e funcionamento do CBAM como um culto, tão sagrado quanto à celebração semanal da ressurreição de Cristo. Considerando se tratar de um grupo protestante de soterologia arminiana ${ }^{5}$, a graça, citada na primeira estrofe, é elemento central para a salvação da alma humana e só é encontrada mediante a busca do homem pelo favor divino. $O$ efeito imediato dessa graça seria a salvação, elemento espiritual e escatológico, seguida pela justificação, elemento espiritual no tocante ao estado do indivíduo, mas material no que se refere ao cumprimento dos preceitos e leis divinas. Este cumprimento só poderia acontecer após o ensino e aprendizado dessas leis, que acontece mediante atuação do Espírito Santo no interior de cada indivíduo, pela leitura bíblica e pela assistência à pregação (Langston, 1983).

A utilização do hino 140 possibilita que se faça um paralelo entre a soterologia arminiana e a matrícula no CBAM. É necessário considerar que, para os batistas, todas as crianças são salvas, até que cheguem à idade do entendimento ${ }^{6}$ e possam decidir-se ou não por Cristo (Maddox, 1952). Portanto, assim como o homem adulto busca a graça divina e aprende a lei pelo Espírito Santo, a criança se matricula no CBAM e ali aprende os princípios considerados adequados, por meio dos professores que, por diversas vezes, são comparados, no periódico O Baptista Mineiro, a ministros, pastores e missionários. A responsabilidade, que recaía sobre os pais e mães de família quanto à educar seus filhos de acordo com os preceitos de sua religião, para que no futuro recebam a graça divina e a salvação, recaía também quanto a enviar seus filhos para que recebessem uma educação que Ihes possibilitasse receber a graça do conhecimento e a salvação dos princípios políticos e sociais difundidos pelo grupo para a vida em sociedade, constantemente representados como democracia, individualismo e federalismo. Podemos, portanto, concluir que a educação oferecida na instituição tinha um propósito transformador que, ao que parece, era espiritual e social.

\footnotetext{
${ }^{5} \mathrm{~A}$ soterologia arminiana ou arminianista é uma interpretação do texto bíblico no que se refere à salvação da alma do homem. Um de seus principais pontos é o livre arbítrio e a capacidade humana de escolher entre a fé em Cristo e a consequente salvação da alma, ou a incredulidade e a consequente condenação ao inferno após a morte. Maiores informações sobre a soterologia arminiana, conforme adotada pelos batistas, pode ser encontrada em Langston (1983).

${ }^{6}$ Os teólogos batistas consultados não definem essa idade em termos numéricos. 
A segunda estrofe do hino pode ser interpretada como a súplica do educador: despertar pecadores e estimular a Igreja pelo seu trabalho. Os vocábulos pecadores e Igreja, analisados conforme a doutrina batista, constituem sinédoques: o primeiro referese aos não-convertidos, que não se agregam em uma classe única, e o segundo ao conjunto de convertidos ou salvos, que formam a Igreja. Unidas essas classes constituem a totalidade das pessoas, exceto pelas crianças que, embora sejam consideradas salvas pelos batistas, ainda não pertenceriam efetivamente a nenhuma das duas classes. Esta expressão aponta a possibilidade de um projeto de educação de adultos, mas também a possibilidade de um projeto evangelístico e pastoral para as crianças que fossem atingindo a idade da razão. Note-se que os vocábulos despertar e estimular aqui utilizados são frequentes no vocabulário educacional. Tal interpretação coincidiria com a tendência educativa sobreposta à evangelizadora pelos missionários norte-americanos, conforme relata Machado (1999).

A última estrofe é uma súplica ao Espírito de luz. Esta não é uma das designações mais frequentes à terceira pessoa da Trindade entre o grupo. A utilização da palavra luz remete também à educação, à luz do conhecimento. Percebe-se que se espera uma atividade educativa e direcional do Espírito, pela qual o fiel teria a oportunidade de realizar a obra divina de transformação do mundo (Langston, 1983). Chamon (2005), ao analisar um hino composto e utilizado por Maria Guilhermina Loureiro de Andrade, interpreta a metáfora da luz como sendo aquilo que permitia ao homem a descoberta das verdades do mundo e, em decorrência disso, o tornava livre e senhor do seu destino.

Tal princípio estaria em conformidade com a fé reformada e refletiria, no campo educacional, o aprendizado pela descoberta e experiência individual. Assim como era esperado pela educadora presbiteriana, os batistas continuamente representavam sua educação escolar como capaz de oferecer ao educando habilidades que o capacitassem à vida ativa em uma sociedade democrática, posicionando-se acerca de suas opiniões, direitos e deveres. E caso esse aluno fosse viver em uma sociedade não-democrática, os batistas esperavam que ali ele se tornasse um campeão baptista, oferecendo até o próprio sangue para transformar a sociedade em que se inseria em uma sociedade democrática, conforme a concepção do grupo (Barbosa, 1920, p.3).

Por fim, pode-se concluir, a partir desta terceira estrofe, que os batistas tinham uma forte expectativa quanto ao efeito disciplinar da instituição que estava sendo fundada. $O$ Espírito de luz que estava sendo invocado pode ser considerado uma referência ao que Foucault (1987) chama de aparelho disciplinar perfeito, ou seja, o olho perfeito a que nada escapa e centro em direção ao qual todos os olhares convergem. Considerando que o grupo crê na doutrina da Trindade ${ }^{7}$, o Espírito de luz que se esperava que executasse a disciplina na instituição, ensinando e dirigindo os indivíduos à utilidade almejada, representada nesta estrofe pela palavra dever, seria a mesma pessoa que Jesus, objeto da admiração e alvo da transformação almejada pelo narrador do hino. Note-se que a pessoa de Jesus é descrita como meigo, vocábulo sinônimo de dócil, e Bom pastor, ou seja, alguém que cumpre adequadamente a sua utilidade.

\footnotetext{
7 Langston (1983, p. 112) define o termo Trindade como a "tríplice manifestação de Deus ou a sua manifestação no Pai, no Filho e no Espírito Santo. [...] Há em Deus três personalidades distintas e divinas, sendo cada uma igual à outra quanto à natureza. No entanto, não há três deuses: Deus é um só." Hist. Educ. [Online] 
Admirar Jesus e ser conduzido pelo Espírito de luz é fazer parte de um círculo disciplinar que os batistas pretendiam difundir a partir da educação escolar. Aqueles que ali se inserissem se tornariam disciplinados e disciplinadores para a sociedade. Assim como Jesus foi capaz de fundar o cristianismo, a partir do treinamento de uma equipe numericamente pequena, e obteve elevados resultados, os educadores do CBAM treinariam poucas crianças naquele primeiro momento, esperando obter fantásticos resultados na implantação da doutrina batista no Estado, no país e no mundo ${ }^{8}$. É notório que a escolha realizada para os níveis de ensino culminava no magistério para as mulheres e no seminário para os homens. Ambas as carreiras são tidas, pelo grupo, como caracteristicamente religiosas e missionárias e podem ser consideradas como disciplinadoras e normalizadoras,

Retornando aos relatos da Ata de abertura, estavam presentes na reunião "diversas creanças, paes das mesmas e diversos visitantes" (50 anos, p. 11). É interessante a importância dada à presença das crianças na assembleia, citadas em primeiro lugar no texto. Observando a já mencionada foto da Primeira Igreja Batista de Belo Horizonte na ocasião da fundação da CBM (50 anos, 1968, p. 13), pode-se perceber que havia um número considerável de crianças entre seus frequentadores. Na referida foto é possível identificar 23 crianças, meninas e meninos, que aparentam estar em idade escolar. Aderem à proposta batista de educação neste momento, enquanto alunos matriculados, 13 crianças $^{9}$.

Os oradores desta assembleia foram o missionário norte-americano e pastor Otis Maddox, o pastor brasileiro Henrique Cockell, além de Manoel Elisbão da Silva, que não possuía cargo eclesiástico ${ }^{10}$. É interessante que, tanto a ordem do discurso, quanto a quantidade de elementos registrados parecem demonstrar a hierarquia entre eles: primeiro discursa o norte-americano, com maior riqueza de detalhes registrados, a seguir o pastor brasileiro e, por último, Manoel. Embora a ata tenha sido redigida por Henrique Cockell, de seu discurso são registrados apenas tópicos, sem nenhuma explicação dos mesmos.

Mesmo que em relato posterior (50 anos, 1968, p. 12), Cockell tenha demonstrado o quanto estava empenhado para a criação da instituição, e suas razões para isso, nos discursos registrados na Ata de abertura apenas Maddox demonstra saber em que, efetivamente, constituíam-se os diferenciais de uma escola batista. Cockell discursou sobre a importância do apoio dos pais ${ }^{11}$, mas não falou sobre nenhuma prática diferente das que aconteciam nas escolas da época, exceto sobre a necessidade de estarem as famílias orando em favor da Escola. Manoel Elisbão apenas manifestou sua alegria e gratidão a Deus, pois via a instituição como "resultado e resposta das orações dos irmãos" (50 anos, 1968, p. 11). Maddox é o único que discorre de maneira mais profunda,

\footnotetext{
${ }^{8}$ Bezerra (1960) demonstra a importância que o trabalho missionário tem para o grupo estudado. É notório que ainda na década de 1920 a Convenção Baptista Mineira enviava seu primeiro casal de missionários a Portugal (O Jornal Batista, junho de 1925).

9 Todos os alunos matriculados neste primeiro momento, com exceção de dois, são identificados em 50 anos (1968).

${ }^{10}$ Manoel Elisbão recebe, na ata, o título de irmão, o que se constitui em indício de ser ele protestante e, provavelmente, batista, mas o iguala aos membros comuns da igreja.

${ }^{11}$ Cockell fala acerca da pontualidade e asseio dos alunos, da importância do dever de casa, do apoio moral à diretora e professores, e da necessidade de estarem orando constantemente em favor da escola. Hist. Educ. [Online] Porto Alegre v. 19 n. 47 Set./dez., 2015 p. 271-288
} 
estabelecendo o que na ata se denomina "Planos da Escola Baptista em Bello Horizonte" (idem, aspas originais). O norte-americano era o único capaz de visualizar em que se esperava que se tornasse a instituição e era quem mais poder tinha de levá-lo a efeito, já que sua esposa era a diretora.

O discurso de Maddox, dos quais foram registrados os pontos principais, revela muito do que era esperado da instituição:

Existe principalmente para educação dos filhos dos Baptistas, aceita, entretanto, crianças de quaesquer paes que desejem confial-as para serem educadas". "O preparo conveniente dos nossos filhos para servirem" e neste ponto mostrou a necessidade este preparo para servir em qualquer esphera mormente na Causa de Jesús. "A razão de ser da escola onde mencionou o ultimo abuso commettido nas Escolas Publicas com a collocação dos crucifixos nos edifícios e tambem a deficiência no ensino secular das mesmas Escolas. Por ultimo fallou sobre "As condições para a existência da escola". (50 anos, 1968, p. 11)

O missionário já possuía um plano de ação traçado, que incluía o público-alvo, os objetivos, a justificativa e as condições para existência da instituição. Tal fato suscita o questionamento acerca da intenção dos Maddox em se estabelecer em Belo Horizonte. Teriam eles vindo para a nova capital e fundado uma escola, ou teriam vindo para fundála?

Era comum que a Junta de Richmond enviasse ao Brasil missionários com a tarefa específica de fundar escolas e seminários. As fontes consultadas para este trabalho não permitem perceber a comissão dos Maddox, nem de Richmond, nem da CBB com a finalidade educacional definida. Tampouco, percebe-se uma decisão pessoal destes norte-americanos nesse sentido. Sua decisão por Belo Horizonte é sempre atribuída à saúde de sua filha Catarina e nunca relacionada diretamente a objetivos educacionais. A maneira, porém, que se desenvolveu a chegada dos Maddox a Minas Gerais e a fundação da EBBH nos levam a cogitar outras possibilidades.

Independente de onde veio a inspiração dos Maddox para a criação de uma instituição escolar na nova capital mineira, é fato que sua experiência em fundação de escolas domesticas no Brasil pode ter-lhes ajudado a desenvolver uma percepção mais aguçada acerca das possibilidades para uma instituição escolar. Mesmo porque anteriormente já haviam sido iniciadas pelo menos duas escolas domésticas batistas em Belo Horizonte, que foram fechadas uma por motivo de mudança da professora para outra cidade, e outra por perseguição religiosa, mas nunca por falta de alunos (50 anos, 1968; Oliveira, 1999; Silva, 1996). Outra possibilidade é que o casal estivesse disposto a se esforçar para alcançar destaque no trabalho educacional em Minas Gerais, suscitando a hipótese de que o campo mineiro representava para os missionários que aqui se instalaram uma possibilidade de maior sucesso em seu trabalho que em outras áreas mais exploradas pela denominação.

Por outro lado é curiosa a afirmação expressa em 50 anos (1968, p. 12) acerca da importância dos Maddox neste projeto: "A vinda da família O. P. Maddox para Belo Horizonte resultou na realização do sonho dêstes pioneiros do trabalho em Minas." Por que esta obra é atribuída tão diretamente a estes missionários? Por que outros missionários com formação escolar mais ampliada que o casal Maddox não assumiram 
esta tarefa $?^{12}$ Nas fontes consultadas não encontrei referência à experiência docente ou administrativa escolar de Ottis antes d'ele vir para o Brasil. Ainda assim, sua obra de maior proeminência no solo brasileiro foi a fundação da EBBH e sua transformação em CBAM. O pastor Maddox, em Minas Gerais, jamais se destacou pelo trabalho à frente de alguma igreja, sendo apenas membro da Primeira Igreja Batista e, posteriormente, das igrejas do Barro Preto e Floresta.

Quando se tornou menos necessário ao trabalho no CBAM, assumiu o cargo de Secretário Correspondente na Convenção Baptista Mineira e não o pastorado de uma única igreja, como era mais comum entre os pastores e missionários batistas. Neste cargo Ottis apenas viajaria de igreja em igreja pelo interior do Estado, sem se fixar em nenhuma delas. É também provável que a escolha de Ottis para um cargo administrativo em detrimento do pastorado se devesse ao fato de Ottis não ter aprendido a falar português corretamente (50 anos, 1968). Isso certamente causou dificuldades de comunicação com a maioria dos membros brasileiros das igrejas ${ }^{13}$, mas nunca com os pastores, que mesmo não sendo norte-americanos usavam 0 inglês. Muitos pastores batistas brasileiros estudaram em escolas protestantes que ensinavam o idioma, como Henrique Cockell $(O$ Jornal Batista, out. 1928), sendo que alguns deles estudaram no próprio CBAM, como Munelar Monclar Maia (50 anos, 1968).

Outra característica a ser ressaltada acerca dos planos para a EBBH expressos no discurso de Ottis Maddox relaciona-se à necessidade de criação de uma instituição escolar protestante em Belo Horizonte. À época, haviam grupos escolares, além de escolas confessionais católicas e uma escola metodista, em funcionamento há quase duas décadas. O discurso educacional público da época constantemente perpassava questões relacionadas à laicidade da educação.

Considerando que era frequente no discurso dos líderes batistas o estímulo à participação política para implantação de um Estado laico e democrático, é de se estranhar que eles não estimulassem a mobilização dos cidadãos batistas em prol da educação laica e gratuita. Percebe-se, no discurso de Maddox, uma tendência a representar a instituição escolar batista como concorrente direta dos grupos escolares e não das confessionais católicas ou protestantes. Além disso, percebe-se o interesse por um projeto educacional próprio, o que tornava o Colégio Izabela Hendrix apenas uma alternativa frente aos problemas que o Maddox e Cockell apontavam na escola pública, mas nunca a solução desejada (50 anos, 1968).

Pela análise dos documentos não foi possível encontrar referências às razões que levavam os batistas a repudiar o sistema de ensino da instituição metodista. A mensagem

12 Ottis era graduado e Efigênia não cursou o ensino superior (Maddox, 2008). A formação dos Maddox era inferior, por exemplo, à formação dos Morgan: ele era mestre em Artes e ela bacharel em Artes. (Prospecto, 1927). A formação tanto dos Maddox quanto dos Morgan ficava aquém dos missionários enviados ao Brasil por Richmond com objetivos expressamente educacionais como, por exemplo, A. B. Langston ou W. C. Taylor, ambos doutores.

${ }^{13}$ Em 50 anos (1968, p. 19), descreve-se um acontecimento em que, ainda no Rio de Janeiro, certa vez o missionário Ottis Maddox, que se valia de um intérprete para celebrar cultos, "afinal, tentou dirigir o trabalho em português. Uma noite, depois de despedir a congregação com oração, uma velhinha veio abraçá-lo e disse-lhe com voz carinhosa: Não te desanimes irmão, Deus compreendeu o que disseste". Por outro lado, Tognini (1993, p. 16), que conviveu com o missionário em Minas Gerais, afirma que ele era um pregador cujas mensagens eram poderosas-embora não especifique se eram proferidas em português. 
da missão batista no Brasil apresentava muitas semelhanças teológicas com a mensagem metodista norte-americana, uma influência que pode ter sido herdada durante o período do Grande Despertar ${ }^{14}$. Em todo caso, o conteúdo religioso do ensino das duas instituições protestantes não seria tão diferente, exceto por princípios distintivos da Igreja Batista entre os grupos protestantes como, por exemplo, o congregacionalismo, que seria ensinado no CBAM com uma roupagem de democracia, republicanismo e federalismo.

É possível, também, que a concorrência não fosse direcionada à escola pública em si, mas à possibilidade de uma influência metodista via relações governamentais nessa suposta laicidade do ensino. Mesquida (1994) relata o quanto esta denominação era influente nos EUA, chegando a atingir até mesmo os presidentes, pelos de seus ideais e reivindicações. Vieira (1990) demonstra como, no século 19, a difusão dos ideais protestantes no Brasil se tornou mais uma maneira de que os liberais maçons dispunham para difundir seus princípios. Em Belo Horizonte, o Colégio Izabela Hendrix tinha boas relações com o governo, chegando a receber um terreno em localização privilegiada ${ }^{15}$ para seu funcionamento (Hendrix, 2004). Mesmo a influência presbiteriana se fazia sentir na educação no estado. Chamon (2005) relata acerca da participação de Maria Guilhermina na reforma educacional de 1906, a convite do presidente do Estado, João Pinheiro. Embora Pinheiro fosse positivista e defendesse a laicidade do ensino, não se pode deixar de considerar a participação de uma presbiteriana, oponente teológica e doutrinariamente aos batistas, na definição dos parâmetros para a educação pública no Estado mineiro.

De acordo com as fontes consultadas, os batistas quase nunca dispunham de relacionamentos tão privilegiados no território brasileiro. No Nordeste era comum que alguns obtivessem vantagens pela manutenção de bons relacionamentos com os coronéis (Feitosa, 1974). Embora alguns dos pastores batistas tivessem envolvimento com a maçonaria, o número desses indivíduos era menos expressivo que entre os metodistas e presbiterianos. Em Minas Gerais, no período pesquisado, ainda não encontrei indícios de manutenção de relações de sociabilidade dos pastores com governantes ou detentores de algum tipo de autoridade. Talvez a necessidade de criar uma instituição de ensino batista se desse como possibilidade de marcar um território educativo propriamente seu, sem que a influência política e social do metodismo ou de outras denominações protestantes viesse a lhes importunar, como acontecia nos EUA.

Embora tenha sido criada em 1918, em 1920 a EBBH já havia sofrido alterações significativas em sua finalidade e abrangência, passando a ser chamada de Collegio Baptista Americano Mineiro. É interessante considerar que estas alterações não

${ }^{14}$ O Grande Despertar foi um movimento de revivificação religiosa ocorrido entre os protestantes dos Estados Unidos, entre as décadas de 1790 e 1840. Suas principais características são a pregação de uma experiência espiritual pessoal, que conduziria a uma vida de santidade. A santificação do fiel se manifestaria, tanto pela conduta piedosa, quanto pela vinculação ativa a trabalhos e projetos de cunho social, como a reforma do sistema prisional, movimento abolicionista, etc. Ver Gonzalez (1991).

${ }^{15}$ A doação, feita pela comissão diretora da nova capital, foi um terreno na Avenida Afonso Pena, esquina com Rua Espírito Santo, para construção de uma igreja e uma escola. Este terreno localizava-se na principal avenida da cidade, defronte à Igreja de São José. 
modificaram as representações sobre a instituição expressas por Maddox na Ata de abertura. Este movimento transformador era contrário à maioria das instituições escolares batistas que, normalmente, eram criadas para uma finalidade e nela permaneciam, sem ampliações ou modificações significativas.

Sabe-se que foram matriculados, em 1918, apenas treze alunos de idades e níveis de escolarização diferentes, a maioria destes eram filhos de missionários ou de famílias batistas. As fontes consultadas neste trabalho não apontam uma razão definitiva para esta transformação. Além das razões anteriormente citadas, relacionadas à representação de modernidade e republicanismo em torno dos grupos escolares e de sua forma de organização, e à concorrência direta com o Colégio Izabela Hendrix, é possível que a transformação da EBBH em Collegio se tratasse da adequação a uma estratégia ${ }^{16}$ maior, de nível nacional e sob a supervisão norte-americana. Afinal de contas, entre os batistas, ostentar o título de Collegio envolvia mais que a abrangência de níveis de ensino: significava fazer parte de um projeto educativo importado dos Estados Unidos, que estabelecia modelos até para os menores detalhes do funcionamento da instituição.

Este projeto envolvia a transformação da instituição de ensino em uma cópia fiel do Collegio Baptista Brasileiro, sediado no Rio de Janeiro para servir de modelo às outras instituições nacionais (Mesquita, 1940). Até mesmo os prospectos de propaganda seguiam modelos parecidos. Seja como for, parece que a transformação agradou os norte-americanos, pois deles veio o recurso financeiro para realizar a aquisição do Palacete Sabino Barroso e os terrenos anexos, no bairro Floresta, onde ainda a instituição permanece em funcionamento.

\section{Considerações finais}

Pode-se considerar que a educação escolar foi uma das principais estratégias utilizadas pelos missionários protestantes norte-americanos para difundir seus ideais em solo brasileiro. Porém, a realização do projeto educacional, pela fundação de escolas e colégios, tinha vários pontos de tensão a se considerar. Dentre estes pontos de tensão pode-se enumerar as expectativas da denominação, tanto nos Estados Unidos, quanto no Brasil. Além disso, os anseios dos participantes da igreja, dos outros protestantes, dos moradores da cidade e as influências debate educacional à época em geral também afetavam o trabalho de implantação da escola.

Estes fatores, atuando em conjunto, faziam com que a posição dos missionários estudados oscilasse entre a estratégia e tática, ora numa posição mais agressiva, com vistas à implantar uma instituição educacional e com ela os princípios da denominação, ora numa posição mais submissa, adequando-se ao projeto da denominação e às expectativas criadas a respeito da cidade. Assim, foi possível alcançar aceitação e apoio, tanto de norte-americanos, quanto de brasileiros, e criar uma instituição de ensino com funcionamento ininterrupto por mais de 90 anos.

${ }^{16}$ Entendo o conceito de estratégia conforme definido por Certeau (1998). Para o autor, estratégia é a manipulação das relações de força que se torna possível a partir do momento em que um sujeito de querer e poder pode ser isolado. A estratégia cria a possibilidade de planos futuros a partir do lugar que se ocupa, permite a previsão e antecipação, e permite o poder de conquistar para si um lugar próprio. A estratégia impõe seu próprio discurso, visando criar lugares a partir de seus modelos abstratos. Torna o outro objeto de suas ações, dominando-o. 


\section{Referências}

50 ANOS: 1918-1968. Belo Horizonte. 1968.

ARCHIVO de notas finaes do Collegio Baptista Americano Mineiro. 1921 a 1930.

AZEVEDO, Israel Belo de. A celebração do individuo: a formação do pensamento batista brasileiro. Piracicaba: Unimep; São Paulo: Exodus, 1996.

BARBOSA, Achilles. A campanha e a educação. O Baptista Mineiro, Belo Horizonte: anno I, n. 1, 1920, p. 3.

BEZERRA, Benilton C. Interpretação panorâmica dos batistas. Rio de Janeiro: Casa Publicadora Baptista, 1960.

CANTOR CRISTÃO. Edição revisada e documentada. $4^{a}$ edição com música. Rio de Janeiro: Juerp/Casa Publicadora Batista, 1971.

CERTEAU, Michel de. A invenção do cotidiano: as artes de fazer. Petrópolis: Vozes, 1998.

CHAMON, Carla Simone. Maria Guilhermina Loureiro de Andrade: a trajetória profissional de uma educadora (1869/1913). Belo Horizonte: UFMG, 2005. 338f. Tese (doutorado em Educação). Programa de Pós-Graduação em Educação, Universidade Federal de Minas Gerais.

CHARTIER, Roger. A história cultural: entre práticas e representações. Rio de Janeiro: Bertrand Brasil, 1990.

CLARK, Jorge Uílson. Presbiterianismo do sul em Campinas: primórdio da educação liberal. Campinas: Unicamp, 2009. 178f. Tese (doutorado em Educação). Programa de Pós-Graduação em Educação, Universidade Estadual de Campinas.

CRABTREE, Asa Routh. História dos batistas do Brasil até o ano de 1906. Rio de Janeiro: Casa Publicadora Batista, 1940.

DALLABRIDA, Norberto. Nascimento da escolarização moderna: cotejo de duas leituras. Perspectiva, Florianópolis: UFSC, v. 22, n. 1, 2004, p. 93-110.

FARIA FILHO, Luciano Mendes de. Dos pardieiros aos palácios: cultura escolar e urbana em Belo Horizonte na Primeira República. Passo Fundo: UPF, 2000.

FEITOSA, José Alves. Breve história dos batistas do Brasil. Rio de Janeiro: Souza Marques, 1974.

FOUCAULT, Michel. Vigiar e punir: história da violência nas prisões. Petrópolis: Vozes, 1987.

GONZALEZ, Justo L. A era dos novos horizontes. São Paulo: Vida Nova, 1991.

HARRISON, Helen Bagby. Os bagby do Brasil: uma contribuição para o estudo dos primórdios batistas em terras brasileiras. Rio de Janeiro: Junta de Educação Religiosa e Publicações, 1987.

HILSDORF, Maria Lucia Spedo. História da educação brasileira: leituras. São Paulo: Thomson Learning, 2007.

IZABELA Hendrix cem anos. Belo Horizonte: Izabela Hendrix, 2004.

LANGSTON, Alva Bee. Esboço de teologia sistemática. Rio de Janeiro: Juerp, 1983.

MACHADO, José Nemésio. Educação batista no Brasil: uma análise complexa. São Paulo: Colégio Batista Brasileiro/Cortez, 1999. 
MADDOX, Ottis Pendleton. Uma interpretação da Bíblia em dois volumes: o Velho Testamento. Belo Horizonte, 1952.

MADDOX, Sarah Gill. A história de Ephigênia Roe Maddox: fundadora do Colégio Batista Mineiro. Belo Horizonte: Colégio Batista Mineiro, 2008.

MELLO, Ciro Flávio Bandeira de. A noiva do trabalho: uma capital para a República. In: DUTRA, Eliana de Freitas (org.). BH: horizontes históricos. Belo Horizonte: C/Arte, 1996. p. 11-48.

MENDONÇA, Antônio Gouvêa; VELASQUES FILHO, Prócoro. Introdução ao protestantismo no Brasil. São Paulo: Loyola, 2002.

MESQUIDA, Peri. Hegemonia norte-americana e educação protestante no Brasil: um estudo de caso. Juiz de Fora: UFJF; São Bernardo do Campo: Editeo, 1994.

MESQUITA, Antônio Neves de. História dos batistas do Brasil: 1907 até 1935. Rio de Janeiro: Casa Publicadora Batista, 1940.

NASCIMENTO, Ester Fraga Vilas-Bôas Carvalho do. Educar, curar, salvar: uma ilha de civilização no Brasil tropical. Maceió: Ufal, 2007.

O COLÉGIO Batista Mineiro: 40 aniversário. Belo Horizonte: Colégio Batista Mineiro, 1958.

O JORNAL Batista, edição do centenário. Rio de Janeiro: Convenção Batista Brasileira, 1982.

OLIVEIRA, Zaqueu Moreira de. Perseguidos, mas não desamparados: 90 anos de perseguição religiosa contra os batistas brasileiros (1880-1970). Rio de Janeiro: Juerp, 1999.

PEREIRA, José dos Reis. Breve história dos batistas. Rio de Janeiro: Junta de Educação Religiosa e Publicações, 1979.

PINEAU, Pablo. Como a noite engendra o dia e o dia engendra a noite revisando o vínculo da produção mútua entre escola e Modernidade. Pro-Posições, Campinas, v. 19, n. 3, 2008, p. 83-103.

PRIMEIRO corpo docente do Colégio Izabela Hendrix em Belo Horizonte (MG). (Fotografia) Disponível em <http://www.siaapm.cultura.mg.gov.br>.. Acesso em 3 jul. 2012.

PROSPECTO do Colégio Batista. Rio de Janeiro: Casa Publicadora Baptista, 1932.

PROSPECTO. Belo Horizonte: Collégio Baptista Americano Mineiro, 1921.

PROSPECTO. Belo Horizonte: Collégio Baptista Americano Mineiro, 1924.

PROSPECTO. Belo Horizonte: Collégio Baptista Americano Mineiro, 1927.

RODRIGUEZ, J. M. Los bautistas en la república del plata. S.n., s.d.: 1936.

SILVA, Armindo de Oliveira. Uma estrela que brilha na floresta: memórias de um educador batista. Belo Horizonte: Colégio Batista Mineiro, 1996.

SILVA, Cleni da. Educação batista: análise histórica de sua implantação no Brasil e de seus desafios no contexto atual. Rio de Janeiro: Juerp, 2004.

TOGNINI, Enéas. História dos batistas nacionais. Brasília: Convenção Batista Nacional, 1993.

VEIGA, Cynthia Greive. História da educação. São Paulo: Ática, 2007. 
VIEIRA, David Gueiros. Liberalismo, masonería y protestantismo em Brasil, siglo 19. In: BASTIAN, Jean-Pierre (org.). Protestantes, liberales y francmasones: sociedades de ideas y modernidade em América Latina, siglo 19. México, DF: Cehila, 1990, p. 39-66.

TACIANA BRASIL DOS SANTOS é bacharel em Teologia pela Faculdade Unida de Vitória, licenciada em Pedagogia e mestre em Educação pela Universidade Federal de Minas Gerais. É integrante do Grupo de Estudos e Pesquisas em História da Educação. Atua como pedagoga na rede municipal de ensino de Sabará/MG.

Endereço: Avenida Saramenha, 622/02 - 31840-220 - Belo Horizonte - MG - Brasil. E-mail: tacianabrasil@yahoo.com.br.

Recebido em 2 de novembro de 2013.

Aceito em 15 de maio de 2015. 